\title{
Correction to: Oocyte cryopreservation in two women with borderline ovarian tumor recurrence
}

\author{
Francesca Filippi ${ }^{1} \cdot$ Fabio Martinelli ${ }^{2} \cdot$ Edgardo Somigliana $^{1,3} \cdot$ Dorella Franchi ${ }^{4} \cdot$ Francesco Raspagliesi $^{2}$. \\ Valentina Chiappa ${ }^{2}$
}

Published online: 17 March 2021

(C) Springer Science+Business Media, LLC, part of Springer Nature 2021

Correction to: Journal of Assisted Reproduction and Genetics (2020) 37:1213-1216 https://doi.org/10.1007/s10815-020-01733-6

The affiliation of Dorella Franchi needs to be corrected as shown below.

Publisher's note Springer Nature remains neutral with regard to jurisdictional claims in published maps and institutional affiliations.

The online version of the original article can be found at https://doi.org/ 10.1007/s10815-020-01733-6

Edgardo Somigliana

dadosomigliana@yahoo.it

1 Infertility Unit, Fondazione IRCCS Ca' Granda Ospedale Maggiore Policlinico, Via M. Fanti, 6, 20122 Milan, Italy

2 Gynaecologic Oncology Unit, Fondazione IRCCS Istituto Nazionale Tumori, Milan, Italy

3 Department of Clinical Sciences and Community Health, Università degli Studi di Milano, Milan, Italy

4 Preventive Gynaecologic Oncology Unit, European Institute of Oncology IRCCS, Milan, Italy 